\title{
El multimedia como semiótica, como medio y como imaginario
}

\author{
Multimedia as semiotics, medium and imaginarium
}

\author{
Joaquín Moreira Alonso jmoreiraalonso@gmail.com \\ http://orcid.org/0000-0002-0024-7762 \\ Facultad de Humanidades y Ciencias de la Educación y Facultad de Información y \\ Comunicación; Universidad de la República (Uruguay)
}

\section{Resumen}

Actualmente, "multimedia" parece ser un término ordinario con un sentido claro. Aparece en los medios especializados y en los medios principales, en documentos de gobierno y corporativos, en la publicidad y en conversaciones coloquiales. Sin embargo, un sentido apropiado y específico para ser usado en los estudios de comunicación está lejos de ser claro. En este artículo critico algunas de las definiciones canónicas e intento establecer algunos puntos útiles para comenzar una discusión acerca del tema. 
En primer lugar discuto la definición según la cual el multimedia es solo la co-ocurrencia de diferentes soportes de mensaje en una sola plataforma porque reduce el multimedia a una simple consecuencia del aparato, sin ningún aspecto comunicacional. Luego discuto la confusión entre características técnicas de los medios digitales y el multimedia en sí.

Como todo medio, el multimedia es mucho más que tan solo los dispositivos y características técnicas que lo hacen posible. Por lo tanto, necesitamos un abordaje más comprensivo del multimedia para los estudios de comunicación que incluya un análisis medial, semiótico y fenomenológico.

Palabras clave: Multimedia; semiótica; estudios de medios; ecología de medios.

\begin{abstract}
Currently, "multimedia" seems to be an ordinary term with a clear meaning. It appears in specialized and mainstream media, in government and corporative documents, in advertising and colloquial conversations. Even though, a proper and specific meaning to be used in communication studies is far from being clear. In this paper, I criticize some of the canonical definitions and make an attempt to establish some useful points to start a discussion about the subject.

Firstly, I discuss the definition according to which multimedia is just the co-occurrence of different message supports in a single platform because it reduces multimedia to a simple consequence of the device, without any communication aspect. Then, I discuss the confusion between technical features of the digital media and the multimedia itself.

As any media, multimedia is much more than just the devices and technical features that make it possible. Therefore, we require a more comprehensive approach for the multimedia in the communication studies which includes a medial, semiotic and phenomenological analysis.
\end{abstract}

Keywords: Multimedia; semiotics; media studies; media ecology.

En los últimos veinticinco años, con la masificación de los medios digitales y la convergencia de diferentes funciones mediales en pocos dispositivos, el término "multimedia" ha cobrado relevancia y circulación. Tanto en los documentos académicos e institucionales como en los medios masivos y la publicidad, lo multimedial aparece en un lugar relevante, sea por ser explicitado de esa forma o por ser ya aceptado como aspecto central. 
Sin embargo, muy poco se ha discutido acerca del aspecto comunicacional de lo multimedial y, en ese marco, para empezar a discutir sobre el multimedia sería necesario preguntarse primero qué es el multimedia. La respuesta a esta pregunta, que posiblemente sea distinta según el contexto en que se realice, nos va a hablar más de nuestra propia concepción de los medios de comunicación y de la tecnología en general que del multimedia en sí. Pero, ya que en general ni siquiera suele hacerse la pregunta, esto ya es un comienzo.

\title{
Un primer intento de definición
}

Un primer abordaje al problema de la definición del multimedia es el analítico-etimológico, esto es, definir el multimedia como aquello que el neologismo "multimedia" expresa, una combinación de varios medios en un solo fenómeno. Si bien esta definición puede parecer simple, si se le agrega la participación de dispositivos digitales en el proceso y la posibilidad de la interactividad nos encontramos con la definición canónica de lo que se suele definir desde la prensa, la publicidad, la industria y parte de la academia como "multimedia".

Sin ir más lejos, ya desde una de las primeras definiciones canónicas se asegura que

\begin{abstract}
el multimedia es cualquier combinación de texto, arte gráfico, sonido, animación y video que es presentada por una computadora. Cuando permites al usuario -quien ve el proyectocontrolar cuáles y cuándo esos elementos son presentados, es multimedia interactivo. Cuando provees una estructura de elementos vinculados [linked] mediante los cuales el usuario puede navegar, el multimedia interactivo se convierte en hipermedia (Vaughan,
\end{abstract} 1993: 3) (1).

Se puede ver que en esta definición temprana (2) ya está mucho de lo que hasta hoy se considera fundamental del multimedia, la combinación de medios, la interactividad, el hipervínculo $\mathrm{y}, \mathrm{y}$ esto es fundamental, el requerimiento de que esa combinación de otros medios sea presentada (delivered) por una computadora, mientras cualquier otra combinación de texto arte gráfico, sonido, animación y video presentada por otro aparato no lo sería. 


\section{Crítica a la noción aparatista de multimedia}

Tal como es presentada por Vaughan y aceptado por gran parte de quienes piensan el multimedia, este sería un fenómeno definido por la computadora, es decir, por el aparato que lo presenta. Si bien esto podría hacer pensar en cierto determinismo tecnológico (McLuhan, 2003), para poder asegurar que esta es una definición medial de multimedia es necesario comprender la diferencia entre aparato y tecnología.

\section{Aparato, tecnología y medio}

Un aparato es un objeto físico que realiza determinado procedimiento de forma automática o semiautomática. Se observa que esta definición convierte al aparato en algo más o menos autónomo ya que, si bien para funcionar puede requerir de determinado input humano e incluso necesita haber sido diseñado y construido, una vez que existe no necesita de la humanidad para existir pues es solamente el objeto físico.

Por su parte, una tecnología es (desde la perspectiva de McLuhan) también el conjunto de conocimientos, prácticas y procedimientos que, aun pudiendo estar asociados a un aparato, trascienden la pura objetualidad de este. El medio constituye así no solo una consecuencia del trabajo humano sino una extensión de sus capacidades (McLuhan, 2003). Así, mientras una red de cables de fibra óptica que atraviesa el mundo es un aparato (podría decirse que es un metaaparato), internet es una tecnología. Incluso, siguiendo a McLuhan pero también a Walter Ong (1993), se podría decir que el lápiz es un aparato y la escritura una tecnología (3).

Siguiendo esta diferenciación, el planteo de Vaughan no problematiza el aspecto tecnológico del multimedia sino su aspecto de aparato, por lo que no podríamos hablar de una definición medial.

\section{Interactividad e hipermediación}

En cuanto a la interactividad, la definición de Vaughan vuelve a coincidir con el concepto general que se tiene de ella. Siguiendo esta concepción, la interactividad aparece en el multimedia cuando hay una respuesta de parte del aparato a determinadas acciones del usuario. 
Por su parte, en su influyente texto Understanding Hypermedia, Bob Cotten y Richard Oliver (1993) plantean una definición de hipermedia que podría incluso pensarse como una definición general del multimedia que unifica los tres términos de Vaughan,

un tipo de experiencia medial enteramente nueva nacida del matrimonio entre TV y tecnologías de computación. Sus ingredientes brutos son imágenes, sonido, texto, animación y video, los cuales pueden ser traídos juntos en cualquier combinación. Es un medio que ofrece 'acceso aleatorio'; no tiene principio, medio o final físico (p. 8) (4).

Sin embargo, en lo relativo a medios basados en las computadoras,

el concepto de interactividad es una tautología. La moderna interfaz de usuario es interactiva por definición pues, a diferencia de las primeras interfaces, como el proceso por lotes, nos permite controlar el ordenador en tiempo real, manipulando la información que se muestra en la pantalla. Por tanto, denominar «interactivos» a los medios informáticos carece de sentido, no hace sino afirmar el hecho más básico de los ordenadores (Manovich, 2005: 103).

Y lo mismo podría decirse de lo que Vaughan llama hipermedia, el hipervínculo no es la característica fundamental del hipermedia sino solamente su operatividad básica. Confundir la etiqueta <a> del lenguaje html con la www (o cualquier otra forma de hipertexto basado en lenguaje de marcado) o el menú del DVD con el video digital es confundir un medio con la operatividad tecnológica (no la tecnología) que lo hace posible.

Una vez más, la definición común cae en el aparatismo al que, considero, podríamos entender como una forma de isomorfismo en el cual el fenómeno social determinante (no igual) de las relaciones culturales que es la tecnología viene a coincidir en su forma con aquel procedimiento que lo sustenta.

\section{El multimedia como imaginario tecnológico}

Este acento tan marcado en el aparato no es algo extraño. Contemporáneamente, el lanzamiento de cada nuevo aparato es pensado como generador de un estado absolutamente nuevo (tal como lo piensan Cotten y Oliver) que marcará, o bien un paso a un nuevo esplendor, o bien el comienzo de una época de decadencia.

En Uruguay, por ejemplo, cuando desde el Poder Ejecutivo se quiso incorporar elementos nuevos a la educación en el marco del programa OLPC (One Laptop Per Child, Una Laptop Por 
Niño, programa desarrollado por el ex director del MIT Nicholas Negroponte), lo que se hizo fue incorporar aparatos con la premisa de que con la sola introducción de las XO en el contexto educativo los escolares iban a mejorar sus capacidades en lenguaje y matemáticas. Sin embargo, para que el Plan Ceibal funcionara fue necesario que se incorporara todo un entramado de investigadores, docentes y desarrolladores que pensaran sobre la interacción de ese aparato con los entornos educativos y domésticos de los niños y docentes.

De un modo semejante, los expertos en tecnología (en aparatos) adquieren el estatus de experto universal. Peter Diamandis o Raymond Kurtzweil (por dar sólo dos ejemplos) son presentados como hombres universales, como los grandes expertos que al entender el funcionamiento de los aparatos tecnológicos son capaces de aportarnos soluciones a problemas que poco tienen que ver con las tecnologías digitales como la educación, la política o la economía. De hecho, resulta sumamente elocuente que también sean llamados gurús.

Y esto alcanza un nivel todavía más profundo cuando estos tecnointelectuales hacen antropología filosófica. En sus planteos sobre transhumanismo, singularidad tecnológica, inteligencia artificial e interacción hombre-máquina muchos de estos tecnointelectuales plantean que el desarrollo de las tecnologías digitales conduce a una superación de lo humano en que las limitaciones físicas y mentales de este serán superadas mediante la integración entre los humanos (a veces como individuos, a veces como colectivo) y las computadoras. Estas ideas son parte de lo que Paula Sibilia (2005) identifica como el proyecto fáustico de la antropología filosófica contemporánea en que la idea moderna del hombre como máquina biológica es sustituida por un paradigma técnico-informacional y el hombre se convierte en un hombre postorgánico.

Es que, hoy más que nunca, las tecnologías (los aparatos tecnológicos) digitales ocupan el rol de significante central de una sociedad que se dice a sí misma "de la información" (Cabrera, 2011). De esta forma, los aparatos se ontologizan constituyéndose en fundamento mismo de la comunicación y del lazo social en lo que Lucien Sfez (1995) denomina "tautismo", palabra que suena a totalitarismo y unifica tautología con autismo.

\section{Hacia una teoría comunicacional del multimedia}

¿Esto significa que la definición de Vaughan sea absolutamente errónea? Desde luego que no. El hecho de que dos cosas no sean lo mismo no quita que una pueda ser importante para la existencia de la otra. De hecho, para retomar los ejemplos ya referidos, no podría haber internet sin cables atravesando el mundo (5) ni escritura sin algún instrumento semejante al 
lápiz (6). Sin embargo, la necesidad del aparato para la existencia del medio no es lo mismo que isomorfismo.

Podríamos, por lo tanto, considerar que la visión de Vaughan sobre el multimedia podría ser catalogada como una definición ingenieril ya que se centra en el aparato y su funcionamiento. Además, no considera la posibilidad de que, tal como la escritura se mantiene a pesar del cambio de los aparatos usados para escribir, existan otras formas de presentación de contenidos multimedia.

No sería, entonces, una definición comunicacional por lo que, aun entendiendo su valor, en este ámbito de trabajo no deberíamos considerarla suficiente sino que debemos repensar el multimedia de un modo que incorpore características mediales, sociales y semióticas. Evitando las tentaciones futurológicas tan comunes y centrándose en "los códigos semióticos de los medios informáticos, sus modos de discurso y sus patrones de recepción por la audiencia" (Manovich, 2005: 50).

\section{Medialidad, semiótica y estética de los nuevos medios}

El cambio de escala que el medio introduce tiene, necesariamente, consecuencias semióticas. Así, la interacción de formas semióticas que antes eran autónomas como por ejemplo el video, el texto y la fotografía en una página de YouTube o la música, la imagen, la red social y el hipervínculo en Spotify, no puede pensarse como la suma de las partes y, a pesar de ser dispositivos centrados en uno de los formatos al que los otros apoyan (video en YouTube y música en Spotify), al cambiar las condiciones de circulación, recepción y, en cierta medida, también las de producción (7), cambia completamente el proceso de semiosis (Verón, 2004) y por lo tanto el modo general de producción de sentido.

Incluso podemos ir más allá y pensar que ese carácter mediático, e incluso sus problemas técnicos, son constitutivos de la estética de todo medio. Siguiendo a Brian Eno (1996), podría decirse que

lo que sea que ahora encuentres raro, feo, incómodo y asqueroso en un nuevo medio seguramente se convertirá en su firma. La distorsión del CD, el temblequeo [jitteriness] del video digital, el sonido de porquería del 8-bit- todo eso será apreciado y emulado tan pronto como pueda ser evitado (p. 283) (8).

Esta confluencia de varias formas en el multimedia constituye una forma medial que determina la estética, las narrativas, las relaciones intertextuales y toda la producción de sentido. De esta 
manera, tal como la primer modernidad tuvo la narración unitaria (ejemplo: novela) y la modernidad de la cultura de masas tuvo la narración serializada (ejemplo: novela por episodios, radionovela, series de TV), la época contemporánea definida por esta convergencia tecnológica y confluencia semiótica tiene en la narración transmedia una de sus formas características (9). Mediante el uso de distintos medios para narrar distintas partes de una historia se constituyen ecosistemas narrativos (Innocenti y Pescatore, 2012) que van más allá de las estructuras de narración contemporánea a la vez que se llega a las audiencias desde distintos lados (Scolari, 2013).

Además, con la popularización del uso de internet y en particular de los tablones de texto, foros, sitios de blogging e incluso YouTube o redes sociales, surgen nuevas formas semióticas creadas por los usuarios como el creepypasta o las narrativas por Facebook y otras que ya existían, como el fanfic, el fanart o el motion comic se potencian.

\section{Medialidad y ecología}

McLuhan (2003: 12) inaugura lo que se llama la "ecología de los medios" según la cual "cualquier tecnología crea gradualmente un entorno humano totalmente nuevo. Los entornos no son envolturas pasivas sino procesos activos" (10). El desarrollo del multimedia en los años recientes modificó el entorno humano y, por consiguiente, la vida de los propios humanos.

$\mathrm{Si}$ las computadoras y sus tecnologías asociadas cambiaron la forma en que las personas trabajan, estudian, se entretienen y, por lo tanto, piensan, al llevar todos los conceptos a la inmediatez de una pantalla (o al menos eso es lo que terminamos creyendo) el teléfono celular (al que por puro anticuados aun no llamamos Ilanamente teléfono) cambió la espacialidad de la acción humana llevando todos los espacios con nosotros.

El teléfono móvil representa una extensión del hogar y, consecuentemente, del ámbito privado. La escena de los móviles repicando y las personas hablando a través de estos aparatos en el tren, el autobús o el metro, ya es parte de la estética global de las nuevas formas de visibilidad y comunicación, sin embargo los asuntos que tratan son de orden estrictamente personal, familiar o laboral, y eso le imprime a la comunicación digital un rasgo cultivadamente local (Winocur, 2009: 47).

Cuando al teléfono celular (ya una forma de multimedia) le agregamos entrada de auriculares, conexión a internet y aplicaciones de trabajo y entretenimiento, el teléfono se convierte en equipo de audio, televisión, computadora, escritorio (11), consola de juegos, etcétera. Así, estemos donde estemos, el espacio físico a nuestro alrededor se convierte, de cierta manera, en sala de estar, oficina, dormitorio, sala de juegos. 
Además, la masificación de los planes de internet móvil y la proliferación de hotspots de Wi-Fi ha hecho que la frontera online-ofline se desvanezca completamente y nuestro entorno sea un entorno psicológicamente híbrido. En este contexto, la relevancia que tienen las redes sociales en la circulación de información socialmente relevante también impacta en la política y define comportamientos de impacto político que puede definir elecciones o llevar a la renuncia de un funcionario importante (Moreira Alonso y Sandoval, 2017).

Finalmente, el crecimiento de las aplicaciones de realidad aumentada, de la que Pokémon GO es solo el ejemplo más comentado (12), introduce al espacio físico en el multimedia dando vuelta la hibridación (13), ya no es el multimedia el que se introduce en el espacio físico real sino este el que constituye parte de aquel.

\section{La interactividad como espacio psicológico}

Aunque la interactividad puede pensarse como un asunto de botones, menús y pantallas (lo cual volvería a una perspectiva ingenieril), considero que desde una perspectiva comunicacional debería ser pensada como una relación psicológica relacional. Debería pensarse como una forma en la que, de modo semejante pero no igual a como lo hacemos con las personas, interactuamos con el medio interactivo asignándole voluntad y cierto sentido de emotividad que nos hace generar un vínculo con él, y cuanto más interactuemos con él más fuerte será ese vínculo. En cierta medida, mediante la interacción con los medios multimedia altamente interactivos, el usuario constituye su propia subjetividad pensando al dispositivo como un interpelante pero también un espejo (Turkle, 1984).

En nuestras tareas con los medios desarrollamos cierta vida, hábitos, rituales que terminamos por internalizar. Si además tenemos una interacción con otras personas online, establecemos un juego simbólico de presentación e interacción (Goffman, 2001) en el que el medio es un factor determinante de la forma en que podemos hacerlo. Así, cuando, luego del proceso de presentación-interacción con los otros intermediado por el medio, las formas de presentación e interacción con el medio se interiorizan y, así como la costumbre elimina las normas de etiqueta en ambientes laborales, se reducen radicalmente las diferencias entre la presentación ese self online y el self offline.

Si al interactuar con dispositivos que explicitan su naturaleza desarrollamos una relación tan densa, cuando la interface comienza a invisibilizarse se hace aún más difícil esa diferenciación. Más allá de que no existe aún una interface de inmersión total, los cascos de realidad virtual, el video 3D, los videojuegos en primera persona, los videos POV (Point Of View, punto de vista) y los MMORPG (Massive Multiplayer Online Role Playing Game, juego de rol en línea 
multijugador masivo) con su desarrollo y progresión de personaje, su entorno altamente complejo, su narratividad emergente (Juul, 2002) y una interacción muy activa con otros usuarios, generan una inmediación (Bolter y Grusin, 1999) que reduce aún más la diferencia entre esas dos dimensiones del self.

De este modo, la interactividad, que es presentada por Vaughan como una mera consecuencia de la presencia de botones y por Cotten y Oliver como derivación del acceso aleatorio, puede ser pensada como un espacio psicológico en que se constituye la subjetividad del usuario.

\section{Al final, un comienzo: una fenomenología de la interface}

Evidentemente este no puede ser espacio de conclusiones. El problema abordado es muy amplio y, al menos para mí, aun no tenemos mucho más que algunos fundamentos a partir de los cuales empezar a pensar el multimedia (14). Aun no terminamos de entender la semiótica del multimedia y apenas estamos empezando a entender como este cambia nuestro entorno y nuestra propia concepción de nosotros mismos.

Tal vez, y esto es sólo una especulación mía, un buen intento de aproximación inicial sea el más humilde. En vez de intentar desarrollar una teoría general del multimedia como algo definido e identificable claramente, podemos empezar a acercarnos a él como interface, interactuar con sus periféricos y comenzar a ver qué pasa.

Con algo de suerte, desde esta fenomenología de la interface del multimedia podamos empezar a entender este nuevo medio que no es tal sino que es un conjunto de medios compuesto a su vez por otros medios que se fusionan, hibridan, remedian y resignifican de formas que trascienden en mucho su puro carácter de aparato.

\section{Notas}

(1) Traducción propia del original en inglés. "Multimedia is any combination of text, graphic art, sound, animation, and video that is delivered by computer. When you allow the user-the viewer of the Project-to control what and when these elements are delivered, it is interactive multimedia. When you provide a structure of linked elements through which the user can navigate, interactive multimedia becomes hipermedia".

(2) Es importante recordar que el primer sitio de la World Wide Web es de 1991 (una versión del sitio se encuentra en http://info.cern.ch/hypertext/WWW/TheProject.html), aunque el CD ROM y la interface gráfica de usuario son anteriores.

(3) En este sentido, la definición de McLuhan de tecnología como equivalente a medio sería formalmente diferente a la que plantea Verón (2004) pero en lo conceptual no sería tan diferente. Según Verón un medio es una tecnología más 
un uso social, sin embargo, Verón identifica tecnología a aparato mientras que McLuhan le asigna a la tecnología un uso social por lo que podríamos decir que, a pesar de la diferencia terminológica, hay una cierta relación entre ambas concepciones de medio.

(4) Traducción propia del original en inglés, "an entirely new kind of media experience born from the marriage of TV and computer technologies. Its raw ingredients are images, sound, text, animation and video, which can be brought together in any combination. It is a medium that offers 'random access'; it has no physical beginning, middle, or end".

(5) No por ahora, en cualquier momento toda conexión por cables puede ser sustituida por redes Wi-Fi o Li-Fi (u otra tecnología semejante) y conexiones satelitales y las computadoras de escritorio por dispositivos móviles y aun hablaríamos de internet. Es decir, los aparatos cambiarían absolutamente en relación a los que había antes pero seguiríamos hablando del mismo medio.

(6) Otra vez, como en la nota anterior, podemos sustituir el lápiz por un cincel, una lapicera o incluso los dedos y aun hablaríamos de escritura.

(7) El cambio tecnológico en las condiciones de producción aparece, entre otros, en el surgimiento de nuevos aparatos de producción (cámaras digitales, interfaces digitales de audio, nuevo software), medios basados en modelos de prosumer (Toffler, 1980) o por la toma de consciencia del cambio en las condiciones de circulación y recepción.

(8) Traducción propia del original en inglés, "Whatever you now find weird, ugly, uncomfortable and nasty about a new medium will surely become its signature. CD distortion, the jitteriness of digital video, the crap sound of 8-bit -all of these will be cherished and emulated as soon as they can be avoided".

(9) Desde luego esto no significa que no haya producción narrativa unitaria ni serial ni tampoco que no haya existido narración transmedial antes de los medios digitales.

(10) Traducción propia del original en inglés, "any technology gradually creates a totally new human environment. Environment are not passive wrappings but active processes".

(11) La metáfora del escritorio en las interfaces gráficas de usuario, cuyo objetivo era "asimilar la computadora al escritorio físico y a los materiales (carpetas de archivos, hojas de papel, bandeja de entrada, cesto de basura, etc.) familiares al trabajador de oficina" (Bolter y Grusin, 1999: 23) (traducción propia del original en inglés, "...to assimilate the computer to the physical desktop and to the materials (file folders, sheers of paper, inbox, trash basket, etc.) familiar to office workers") hoy ya se ha naturalizado y devenido catacresis e, incluso, se invierte el orden de la metáfora, decimos que vamos a tirar una idea a la papelera de reciclaje o que tenemos tal o cual cosa en una carpeta usando como referencia metafórica una metáfora ya asumida como literal.

(12) Si bien Pokémon GO es, hasta ahora, el que logró más repercusión, existen otros ejemplos de juegos de realidad aumentada anteriores (como Ingress) o con desarrollos visuales más complejos y relacionamiento con el entorno más orgánico (como Father. IO) y varias aplicaciones turísticas o comerciales centradas en diferentes usos de la realidad aumentada.

(13) Aunque esta inmersión del espacio "real" en la narrativa multimedial a escala masiva ya existía en algunos ejemplos de Juegos de Realidad Alternativa (ARG por sus iniciales en inglés) tales como The Beast de 2001 (realizado para la promoción de la película Al: Artificial Intelligence)

(14) En ese sentido es esperanzador pensar que, tal como dice McLuhan (2003), somos capaces de pensar un medio con cierta completitud cuando otro medio posterior lo convierte en su contenido. Esa desolación que se puede sentir al pensar lo difícil que es pensar los medios multimedia, al menos deja de ser una desolación solitaria. 


\section{Bibliografía}

Bolter, J. D. y Grusin, R. (1999). Remediation: Understanding New Media. Cambridge: MIT Press.

Cabrera, D. H. (2011). Comunicación y Cultura como Ensoñación Social. Madrid: Fragua.

Cotten, B. y Oliver, R. (1993). Understanding Hypermedia. London: Phaidon.

Eno, B. (1996). A year with swollen appendices. London: Faber and Faber.

Goffman, E. (2001). La presentación de la persona en la vida cotidiana. Buenos Aires: Amorrutu.

Innocenti, V. y Pescatore, G. (2012). Dalla crossmedialità all'ecosistema narrativo. L'architettura complessa del cinema hollywoodiano contemporaneo. En Zecca, F. (Ed). II cinema della convergenza: industria, racconto, pubblico (pp. 127-138). Milano: Mimesis.

Juul, J. (2002). The Open and the Closed: Game of emergence and games of progression. En Mäyrä, F. In Computer Games and Digital Cultures Conference Proceedings (pp. 323329). Tampere: Tampere University Press.

Manovich, L. (2005). El lenguaje de los nuevos medios. Barcelona: Paidós.

McLuhan, M. (2003). Understanding Media. Berkeley: Ginko Press.

Moreira Alonso, J. y Sandoval, L. (2017). La horda digital: Remediatización de la esfera pública y acción política. En Colectivo Entre. entre: Ensayos sobre lo que empieza y lo que termina (págs. 168-189). Montevideo: Estuario.

Ong, W. (1993). Oralidad y escritura: Tecnologías de la palabra. México DF: FCE.

Scolari, C. A. (2013). Narrativas Transmedia: Cuando todos los medios cuentan. Barcelona: Planeta.

Sfez, L. (1995). Crítica de la Comunicación. Buenos Aires: Amorrutu.

Sibilia, P. (2005) El hombre postorgánico: cuerpo, subjetividad y tecnologías digítales. Buenos Aires: Fondo de Cultura Económica.

Toffler, A. (1980). La Tercera Ola. Barcelona: Plaza y Janes.

Turkle, S. (1984). The second self: Computers and the human spirit. New York: Simon y Schuster.

Vaughan, T. (1993). Multimedia: Making it work. Berkeley: Osborne, McGraw-Hill.

Verón, E. (2004). La semiosis social: fragmentos de una teoría de la discursividad. México DF: Gedisa. 
Winocur, R. (2009). Robinson Crusoe ya tiene celular: la conexión como espacio de control de la incertidumbre. México DF: Siglo XXI. 